\title{
Cartaphilus
}

Revista de investigación y crítica estética

\section{LA HETEROGENEIDAD DEL YO EN FERNANDO PESSOA, ANTONIO MACHADO Y MIGUEL DE UNAMUNO \\ SELF HETEROGENEITY IN FERNANDO PESSOA, ANTONIO MACHADO AND MIGUEL DE UNAMUNO}

\section{PATRICIA TERESA LÓPEZ RUIZ}

\author{
UNIVERSIDAD DE MURCIA
}

Resumen: El presente trabajo tiene como meta abrazar un tema que se venía arrastrando de manera progresiva desde el Romanticismo: la despersonalización ante la existencia de un ser múltiple, y que alcanzó cima con el universo creativo de Fernando Pessoa. No obstante, y debido a la conciencia del fracaso de la razón al intentar aprehender una realidad cambiante, escritores como Antonio Machado y Miguel de Unamuno -de manera coetánea al lusitano- también emprendieron esa canalización del ser, como un yo desgarrado, a través de sus obras. La teleología en cada uno de ellos era distinta. No obstante, en mayor o menor medida, los tres encontraron sustento en la filosofía empirista y el escepticismo, y creyeron en una omnipresente textualidad. Textualidad que desdibujó límites antagó- nicos y que los adentró en un espacio de falsedad y superchería, de espejismos irrealizados o de juego tomado en serio.

Palabras clave: yo; heterogeneidad; apócrifo; heterónimo; personalidad.

Abstract: The ensuing work aims at tackling an issue which had been progressively flourishing ever since the days of Romanticism: depersonalization in the presence of a multiple being, which reached its peak within Fernando Pessoa's creative universe. Notwithstanding this, and due to the awareness of the reason's failure at apprehending an ever-changing reality, such writers as Antonio Machado and Miguel de Unamuno -the latter a contemporary of the Lusitanian- also undertook that channeling of the being as a ragged self throughout their works. Teleology was 
different in each of them. However to a greater or lesser extent, our authors nourished on empiricist philosophy and skepticism, and set their belief in a pervasive textuality. Opposing boundaries were blurred by this textuality, which introduced them into a deceit and swindle realm, abundant with unfulfilled smoke and mirrors or seriouslytaken games.

Keywords: I; heterogeneity; apocryphal; heteronym; personality.

Yo me imagino a mí mismo en y te invito a concebir el mundo en el que.

(Levin)

Es una realidad que, dado que se trata de tres de los escritores peninsulares más importantes de principios del siglo $x x$, son innúmeros los estudios que se han llevado a cabo sobre ellos, en los que el tema de la multiplicidad del yo no ha quedado al margen. Sin embargo, el interés por realizar este trabajo reside en que, si bien habíamos hallado algunos libros $u$ otras publicaciones que afrontaban un estudio comparativo de dos de nuestros autores -es el caso fundamentalmente de una de las obras de Lourenço-, no residía en nuestro conocimiento la existencia de ninguno que aunara a los tres, quedando Unamuno en dicha comparativa casi siempre relegado. El propósito con que se concibe es con la razón de ser conscientes de las similitudes y diferencias que se hayan establecido entre las obras de nuestros tres escritores, tan distintas y semejantes, a la vez de como un intento de recopilación de algunas de las discusiones que la cuestión de la heterogeneidad del yo ha suscitado, para arrojar bien razonamientos o bien ejemplificaciones que iluminen y aclaren algunas de las controversias expuestas.

A la hora de introducirnos en este trabajo, no debemos pasar por alto el tremendo martillazo que Nietzsche asestó a la filosofía occidental, a la moral y a la religión, destruyendo las bases sobre las que se asentaba ontológicamente la esencia de lo humano. Esto, sumado a que la razón comenzaba a mostrarse como algo insuficiente para aprehender la existencia humana, fue causa de un estado de confusión y lobreguez que promovió a los escritores a canalizar el problema de la personalidad -que sentían habitar en ellos- por medio de la escritura. Ya los románticos apostaron por la despersonalización del yo, con miras a alcanzar la universalidad, pero a estos les siguieron otros muchos autores sabedores del distanciamiento entre el yo autorial y textual que, con diversas estrategias y juegos literarios, apuntaron hacia la creación de un calidoscopio con que bucear en su interior. Sin embargo, no fue hasta la labor de F. Pessoa cuando esto dinamitó. A ello se debe su presencia en este estudio. Partiendo del que creemos que es el verdadero padre de la heteronimia nos proponemos atender a los móviles y cimientos que animaron a estos tres autores a sumergirse en tal 
arriesgado y complejo universo literario.

\section{Contexto}

Si al sobrevolar la obra de estos tres autores es fácil recordar un interés por los problemas de la personalidad, la otredad y la diferenciación entre yo autorial y yo textual como vientre común que las acuna, si nos detenemos, nos encontramos con tres escritores peninsulares de principios del siglo $\mathrm{xx}$, en los que habitaba una profunda decepción por la situación social y política de sus países y que, con mayor o menor agrado, tuvieron que estar receptivos al movimiento de vanguardias. Como bien afirmó el lusitano con respecto a Portugal y, si tomamos el nombre de la revista como metonimia del arte de vanguardias, por extensión en la Península, en esos años solo había dos cosas importantes: el paisaje y Orpheu. No obstante, a la hora de contextualizar a nuestros escritores, debido a la escasez de espacio, seguiremos la recomendación de Pessoa: "Así que dejo el paisaje y comienzo y termino por Orpheu. El paisaje está ahí siempre y puede ser contemplado por aquellos que quieran. Orpheu está ahí pero realmente no puede ser leído por todos" (Pessoa,1987: 213-214), y nos quedaremos con cómo reaccionaron nuestros autores ante las vanguardias.

Al abordar la figura de Fernando Pessoa en lo referente a las vanguardias, si bien no podemos dudar de que fue uno de los escritores que impulsó la entrada de la literatura europea y de estos movimientos en su país, hallamos dos ideas: lo expuesto explícitamente por él y lo desarrollado por uno de sus heterónimos: Álvaro de Campos, que, aunque algunos críticos no lo consideran opuesto (apoyamos esta idea), otros lo presentan de una manera que resulta contradictoria con respecto a lo dicho por F. Pessoa a quien le ocurren las cosas (que diría Borges), lo cual tampoco sería extraño, dada la absoluta separación que hay entre el escritor lusitano y sus heterónimos.

En una carta que Pessoa le dirigió a Armando Côrtes-Rodrigues (19 enero de 1915), le confiesa:

Usted sabe bien que (por superiores que sean como artistas) como almas, propiamente, no cuentan, pues no tiene ninguna de ellos la conciencia (que en mí es cotidiana) de la terrible importancia de la Vida, esa conciencia que nos impide hacer arte meramente por arte [...] No es una crisis como para lamentarme. Es la de encontrarse solo quien se adelantó demasiado a los compañeros de viaje - de este viaje que los demás hacen para distraerse y yo encuentro tan grave (Pessoa, 1987: 23-27).

Sin embargo, aunque Pessoa criticó este "arte por el arte" de raíz europea, uno de sus heterónimos se manifiestó con estilo futurista: "Oh ruedas, oh engranajess, $r-r-r-r-r$ - eterno! / iFuerte espasmo retenido de los maquinismos furiosos! /[...]/ y me arde la cabeza de querer cantaros con el exceso / de 
expresión de todas mis sensaciones" (Pessoa, 2015: 75). Ante esto, algunos estudiosos, como Marú Ruelas consideran que el poeta portugués -bajo el nombre de Álvaro de Campos- se convirtió en "un vanguardista nervioso, mórbido y melancólico" (Ruelas, 2010: 102). Por el contrario, otros, como Lourenço, admiten un cierto vanguardismo en las Odas Triunfales del heterónimo que nos ocupa, pero aclaran que: "nunca fue verdaderamente un futurista [...] su visión del mundo no es la del ingeniero que observa pragmáticamente las cosas que le podrán ser útiles, sino el mirar desinteresado del poeta que ya no distingue lo que es exterior y lo que es interior" (Lourenço, 1997: 109).

Nos decantamos más por esto último, pues ese canto a la Modernidad que realizó Álvaro de Campos, pudo venir impulsado por el propio interés poético del autor por ser múltiple, por sentir todo de todas las maneras. Esto, y no la exaltación ante ese nuevo mundo al que cantó con gran ironía, pudo ser lo que lo impulsara a introducirse en el interior de las máquinas en un momento en que la sociedad celebraba la II Revolución Industrial. Como Lourenço (1997) afirma, Álvaro de Campos no solo elogió lo útil (característico de los futuristas) sino también lo inútil, pues su aspiración era ser universo: "ioh grandes banalidades, útiles, inútiles / oh cosas modernas, oh mis contemporáneas, forma actual y próxima / del sistema inmediato del Universo!" (Pessoa, 2015: 83). No obstante, el que no llegara a ser del todo futurista no quita para que Álvaro de Campos mostrara ciertos tintes vanguardistas al defender, como muestra Lourenço (1997), la no popularidad del arte.

Frente a Pessoa, Machado, a pesar de poseer concepciones cercanas a la filosofía de Heidegger, discrepó del filósofo en cuanto al arte nuevo y se mostró más resistente que el poeta lusitano. Heidegger junto con Ortega, y como refleja Martínez López siguiendo un estudio de Adorno, apoyaba los movimientos de vanguardia, pues: "el arte de vanguardia, selectivo, minoritario, también tiene un fondo elemental, bárbaro, nihilista y lúdico que lo acerca a su tiempo y a su época" (Martínez, 2013: 13). Por el contrario, Machado, a través de Juan de Mairena nos mostró su respaldo a lo popular y natural: "En nuestra literatura decía Mairena- casi todo lo que no es folklore es pedantería" (Machado, 2016:192). No obstante, como expresa Lourenço (1997), aunque Machado siguiera transmitiendo su desilusión con lo vanguardista, intentó comprenderlo, a través del inventor de la máquina de trovar: J. Meneses.

Fue en su Discurso de Ingreso en la Academia de la Lengua, nunca pronunciado, pero redactado en 1931 y recogido en Los Complementarios y otras obras póstumas (1957), cuando incidió de nuevo en su antivanguardismo. Como se reproduce, Machado criticó a Válery y a Jorge Guillén de: "poetas sin alma." Recordemos cómo, años antes, Pessoa había expresado: "como almas, propiamente, no cuentan" (Pessoa, 1987: 23). Es más, Machado, el autor de la célebre frase: "la poesía es palabra en el tiempo" (Machado, 2016: 111), no podía estar de acuerdo con los postuladores de la poesía pura, quienes tendían a 
"emanciparse del hic et nunc, del tiempo psíquico y el espacio concreto en que se produce su vida individual" (Machado, 1957: 122). El autor de Castilla, como buen discípulo de Bergson, no podía aprobar la creación de unas imágenes que señalaban a una intuición imposible, al carecer esta de experiencia vital.

Nuestro otro escritor, Unamuno, es del parecer de Machado. En su Sentimiento trágico de la vida, vinculado a su obsesión por el misterio de la mortalidad, alegó:"el hombre adopta distintas actitudes y busca por varios modos consolarse de haber nacido [...] y han inventado la monserga del arte por el arte" (Unamuno, 1950: 338). Asimismo, en Teresa, hallamos una clara oposición al nuevo arte. De hecho, Unamuno hizo de Rafael un escritor de rimas becquerianas, en unos años en que todo lo referente al Romanticismo se encontraba pasado de moda: "Lo que no pude conseguir es que Rafael se reconciliase, ni siquiera en parte, con futuristas, ultraístas y demás cerebrales sin corazón, como él les llamaba" (Unamuno, 2000: 20).

Si tras lo experimentado como lectores de F. Pessoa podíamos dudar de que lo expresado por Rafael no fuera lo mismo que lo pensado por Unamuno, él mismo se encargó de aclarlo: "Parecíanle, como a mí me parece, que esos supuestos revolucionarios estéticos y literarios de ultra [...] no cumplen sus propios propósitos y promesas" (Unamuno, 2000: 64).

Como hemos podido comprobar, Machado y Unamuno se opusieron de manera evidente al nuevo arte, mientras que Pessoa se mostró algo más receptivo. Sin embargo, si perseguimos sus obras, los tres hundieron la mirada en su mundo interior: ¿qué es esa construcción de personajes -señal de la heterogeneidad de su yo- si no un intento de mundificación de lo interno y subjetivo?, ¿no serán sus artificios literarios un anhelo por reflejar en un drama las múltiples y contradicctorias ideas internas? y, por ultimo, ¿no tendrá algo de vanguardista su intento por ir más allá de la realidad física, que nos muestra al individuo como ser unitario (un pintor realista lo dibujaría así), y plantear la esencia del sujeto como la de aquellos borgianos senderos que se bifurcaban?

\section{Tres teleologías}

Para ese intento por mundificar la heterogeneidad de su yo e ir más allá de la realidad física, nuestro tres autores confiaron en la escritura, pero cada uno con una teleología distinta. En cuanto a Fernando Pessoa, anhelaba el "ensanchamiento de la conciencia de la humanidad" (Pessoa, 1987: 26), es decir, la universalidad, una universalidad que sentía que ya habitaba dentro de él pero que carecía de nexo. A esto se le sumó su deseó por encontrar un concierto a lo que algunos han calificado de personalidad histérica. Tal como recoge Ruelas: "En portugués, "pessoa" [...] y viene del latín persona, que significa "máscara de los actores romanos." Es decir, en el nombre de Pessoa porta su condición de mixtificación, de máscara, de personaje de ficción; el ser que puede ser todos y ninguno" (Ruelas, 2010: 114-115). Ser todos y ninguno, volar otro, es lo que se 
propuso con la creación de sus heterónimos. Una práctica que ya tenía desde la infancia echada sus raíces: "desde niño tuve tendencia a crear en torno a mí un mundo ficticio, [...] recuerdo, así, el que me parece haber sido mi primer heterónimo o, mejor, mi primer conocido inexistente -un tal Chevalier de Pas de mis seis años" (Pessoa, 1987: 44). Este deseo constante y temprano del poeta por despersonalizarse ha provocado que algunos lo hayan calificado como una personalidad histérica; sin embargo, otros, como Octavio Paz rechazan esa idea pues, como señala Ruelas: "si lo hubiese sido, no habría sido capaz de encauzar su imaginación-obsesión y la historia de la literatura no contaría con su legado" (Ruelas, 2010: 104). El ensayista mexicano, tal como recoge Ruelas, declara: "el neurótico padece sus obsesiones [...] el creador es su dueño y las transforma" (Paz, 1994: 156. Apud Ruelas (2010)). Paz veía más a Pessoa como el constructor de un juego, al que hay que jugar en serio, como decía Cortázar (en cuyo juego, también creó personajes: cronopios, famas y esperantos). Sin embargo, el propio Pessoa, en la carta con que le responde a Adolfo Casais Monteiro su pregunta acerca de la génesis de los heterónimos, alude a esa personalidad múltiple y confiesa: "El origen de mis heterónimos es el profundo rasgo de histeria que existe en mí. Estos fenómenos, [...] no se manifiestan en mi vida práctica, exterior y de contacto con los demás; [...] los vivo yo a solas conmigo" (Pessoa, 1987: 43). Pues, como sentenció Schelegel y recoge Pablo de A. Cobos:

Trasladarse arbitrariamente, no solo con la razón y la fantasía sino con toda el alma, ora a ésta, ora a aquella esfera, como quien se traslada a otro mundo; renunciar libremente a ésta o a aquella parte del propio ser y limitarse totalmente a una tercera; buscar y encontrar, ora en este, ora en aquel individuo su unidad y su totalidad, y olvidar intencionadamente los otros individuos: esto solo puede hacerlo un espíritu que en cierto modo contenga en sí una pluralidad de espíritus y todo un sistema de personas, y en cuyo interior el Universo [...] haya llegado a su total desarrollo y madurez (Cobos, 1972: 81).

Aunque esa histeria la viviera hacia dentro, cuando construyó ese universo literario a partir de esa personalidad neurásica, no aspiraba a contar su mundo interior sino, como hemos anticipado, a hacer de él el universo entero. Como lo fue para Borges, y recoge Román Facundo Espino en su tesis: "postular un yo y querer expresarlo conduce a querer expresar la "vida entera", [...] suponer un yo unitario reúne una sucesión divergente e innúmera de sensaciones" (Espino, 2015: 96).

Es más, en el Ultimatum que escribió su heterónimo Álvaro de Campos, hay un apartado dedicado a esa abolición de la personalidad, en el que, como resultado de esa operación, llega a sostener que en el arte es necesaria la "abolição total do conceito de que cada indivíduo tem o direito ou o dever de exprimir o que sente. Só tem o direito ou o dever de exprimir o que sente, em arte, o indivíduo que sente por vários" (Almeida, 2014: 162). 
Por tanto, al aspirar a ser universo, en Pessoa, igual que en Borges, surge la figura del autor como hacedor. Como vemos en los versos: "de la amargura de lo que nunca seré", ese querer ser hacedor surge, claro está, de un deseo de universalidad, pero también, y fusionado a esto, de la consciencia de los límites de la vida humana y de la irrealidad del yo más allá de ser un conjunto de percepciones instantáneas, es decir, surge de que, como sentenció Borges: "Yo estoy limitado a este vertiginoso presente y es inadmisible que puedan caber en su ínfima estrechez las pavorosas millaradas de los demás instantes sueltos. Convendréis conmigo en la absoluta nadería de esas anchurosas palabras: Yo, Espacio, Tiempo" (Espino, 2015: 94). Esto y el hecho de que, como manifiesta Vila-Matas y recoge Pozuelo Yvancos,

cuando se habla de la vida [...] se suele relatar lo que esa persona llevó a cabo [...] Y olvidamos que las vidas de las personas no son solo eso: cada trayectoria se compone también de nuestras pérdidas y nuestros deperdicios, de nuestras ominisones y nuestros deseos incumplidos, de lo que una vez dejamos de lado, no elegimos o no alcanzamos de las numerosas posibilidades que en su mayoría no llegaron a realizarse. [...] Y me atrevo a pensar que es precisamente la ficción la que cuenta eso" (Pozuelo, 2010: 78).

también lo encontraremos, al igual en Pessoa, en Machado y Unamuno. Tanto este incesante movimiento del devenir como el hacer del yo un conjunto de percepciones instantáneas, conduce a nuestro poeta a crear un -ismo: el sensacionalismo. En una carta a un editor inglés, al que le pregunta si querría publicar una Antología de poesía "sensacionalista" portuguesa, termina revelándole su paganismo y su intento de "llevar a la práctica en la medida de lo posible esa desintegración espiritual que proclamo. Si alguna vez soy coherente, es solo como incoherencia de la incoherencia" (Ibid: 132). Lo que resulta muy a cuento con ese yo como conjunto de percepciones instantáneas y mutables del que venimos hablando y que viene a resolverse en el sensacionalismo de la obra pessoana. Como indica Marú Ruelas (2010): Pessoa "afirmaba que la base de la poesía es la sustitución del pensamiento por la sensación" (p.101). Sentir todo de todas las maneras son las alas que tomó nuestro escritor para volar otro.

En relación a Machado, podemos decir que lo que este anhelaba era conocerse a sí mismo, pero sentía que el ser se encontraba incompleto en su mismidad, por ello, en Los complementarios, comenzó a dibujar el boceto de sus primeros apócrifos, misión que alcanzó su punto más álgido con Abel Martín y Juan de Mairena, aunque estas voces, al contrario de lo que sucede con el lusitano, nunca llegaran a desligarse del todo del yo biográfico. Para lograr un distanciamiento de su yo, Machado recurió tanto a la ironía como al carnaval. Marú Ruelas, al sentenciar que en Machado el fondo es casi siempre el mismo mientras que la forma -cuando quien habla es un apócrifo- sufre transformación; afirma que nuestro poeta, "aprovechando el enmascaramiento, explota la crítica burlesca e irónica" (Ruelas, 2010: 92). Sin embargo, 
consideramos más enjundioso pensarlo al revés, es decir, ver en la ironía un instrumento de construcción de máscaras. Si buscamos en el Diccionario de la Real Academia (ed. vigesimo primera) la palabra: ironía, nos asegura: "figura retórica que consiste en dar a entender lo contrario de lo que se dice." De este modo, vemos en la ironía un fenómeno lingüístico que resulta ideal para introducirse en los vacios del lenguaje, en lo que dice y no dice, y, por tanto, ideal para alumbrar una adhesión a nada, una visión escéptica, puesto que destruye todo aquello que presenta una ilusión definitiva. "Ya nos dijo Kierkegaard que el serio existencial descubre en sí mismo la fuente de comicidad que escapa al serio del hombre limitado, la capta y se baña en ironía para no quedarse petrificado en la finitud de la afirmación" (Cobos, 1972: 26).

Juan de Mairena es un evidente teatro de voces irónicas, es más, dirigiéndose a nuestro otro autor: Unamuno, Machado afirma:

esta tu filosofía, / que llamas diletantesca, / voltaria y funambulesca, / gran Don Miguel, es la mía. / Agua del buen manantial, / siempre viva, / fugitiva; / [...] / ¿Constructora? / -No hay cimiento ni en el alma ni en el viento-. Bogadora, / marinera / hacia la mar sin ribera (Barjau, 1975: 108)

Dilentantesca porque orilla el filosofar académico; voltaria, puesto que busca darle la vuelta a todo y funambulesca, a causa de las piruetas irónicas de las que venimos hablando. Según Barjau, la ironía que subyace en las páginas machadianas es una ironía universal, es decir, una ironía que "presenta todo desde el punto de vista de su insuficiencia. No es una actitud nihilista porque, en su versión romántica por lo menos, es una aspiracion indefinida a lo perfecto" (Barjau, 1975:78). La ironia es lo contrario a la restricción que supone toda afirmación, es otro de los modos como tiene lugar esta indefinida ampliación del ámbito de lo pensable e imaginable postulada por Mairena" (Ibid: 82), es "una posibilidad de comprensión e interiorización de todo lo humano real y posible" (Ibid: 76).

Como comentábamos, esta ironía permite un distanciamiento del yo, una salida de uno mismo. Esto es también lo que sucede con el carnaval. Como nos indica Barjau: "Lo carnavalesco, el uso de la máscara, -o de las máscaras- es entonces una descompresión de la identidad del yo. Aquí la conexión entre la máscara y el apócrifo. Usar la máscara es contrario a ser fieles a nuestra personalidad" (Ibid: 87). El mismo Mairena expresa: "se dice que el Carnaval es una fiesta llamada a desaparecer. [...] Porque lo esencial carnavalesco no es ponerse careta, sino quitarse la cara. $Y$ no hay nadie tan avenido con la suya que no aspire a estrenar otra alguna vez" (Machado, 2016: 164-165).

Esta máscara, en Machado, desemboca en la creación de apócrifos, creación con que nuestro poeta quiere tambalear lo definitivo, ya que, por serlo, podía ser falso. Por ello, no es de extrañar que nuestro autor, al exponerle Unamuno su desazón por, al morir, perder la identidad; le contestara: "Cabe otra 
esperanza, que no es la de conservar nuestra personalidad sino la de ganarla. Que se nos quite la careta, que sepamos a qué vino esta carnavalada que juega el universo en nosotros y nosotros en él" (Barjau, 1975: 84).

Tanto para Pessoa como para Machado, el esceptimismo resultó ser cuna de la heterogeneidad del yo que reflejaron en sus obras como. Tal como decía Mairena: "el escepticismo de los poetas suele ser el más hondo y el más difícil de refutar" (Machado, 2016: 190). Esta corriente filosófica califica de imposible el conocimiento absoluto, es más, considera que si algo puede ser aprehendido por la mente debe ser tomado como algo cambiante y de ninguna manera como algo absoluto. F. Pessoa en el Últimatum que escribe Álvaro de Campos sostiene: "Em filosofia: Abolicao total da Verdade como conceito filosofico" (Almeida, 2014: 162).

Para llevar a término esto que predicaba, fue para lo que F. Pessoa creó los heterónimos: quiso aglutinar en ellos el mayor número de maneras de pensar distintas. El lusitano no se consideró nunca un filósofo, pero sí que podemos afirmar (frente a la "vieja querella" entre poesía y filosofía, que Vicente Cervera nos presenta en su libro: La poesía y la idea) que su poesía, en contraposición a la que Cervera (2007) menciona como poesía del mythos, se nutre de la filosofía e incluso, como nos indica Diego Sánchez Aguilar en su introducción a la poesía de R. Juarroz, sobrepasa límites que para la filosofía -apegada siempre a la lógica- son imposibles:

El acto poético aparece, una vez que asume que es una vía apta para la reflexión, como el ámbito del pensamiento que puede superar las limitaciones de la filosofía, ampliando con el pensamiento simbólico, fragmentario y emocional, una realidad que la filosofía, por sus necesidades científicas, ha reducido a lo demostrabre (Juarroz, 2014: 20).

Este escepticismo de raíz filosófica del que venimos hablando estaba ya en el empirismo. Pessoa, como recogen Ruiz y Cervera, es consciente de que es "imposible acceder al conocimiento de las cosas, por lo que nuestra resolución deberá ser la del que reniega de sus facultades racionales, inútiles, en virtud de la consecución de la paz interior sólo obtenida mediante el uso sistemático de la epojé" (Ruiz \& Cervera, 1988-1989: 151). Esta suspensión del juicio provoca una omnipresencia de las sensaciones, lo que deviene en la epojé del nuevo artista de la que habla Pozuelo, del artista "quien desconfía de sí y entrega el vivir a la conciencia, a la mirada de otro que es / no es él mismo" (Pozuelo, 2010: 225). Nuestro poeta poseía esta mirada: "Me siento múltiple. Soy como una habitación con innumerables espejos fantásticos que distorsionan en reflejos falsos una única realidad anterior que no está en ninguno y está en todos" (Pessoa, 1987: 58). De esta forma, llegamos de nuevo a la necesidad que tiene el poeta de crear heterónimos para atribuirle a cada uno una emoción y, así, explicarse a sí mismo, pero asumiendo la ironía de que lo único logrado será despersonalizarse: 
"habiéndome acostumbrado a no tener creencias ni opiniones... en breve terminaré por no tener ninguna personalidad, excepto la personalidad expresiva" (Pessoa, 1984: 49). Por lo cual, podemos afirmar de Pessoa que, si algo es, es una identidad literaria.

No queremos dejar de mencionar que hay algunos estudiosos como Judith Balso y Vásquez que no consideran que nuestro escritor sea escéptico, para lo cual alegan:

¿Constituirá entonces un escepticismo? He ahí una opinión muy extendida y, más que una opinión sobre esos "poemas-libros", un modo de leerlos, que se dedica a tomar cada poeta como una refutación de los otros. Nos parece que una de las principales interpretaciones incorrectas con respecto a Pessoa consiste en haber confundido Ser y Verdad y haber atribuido a esta problemas correspondientes a aquel. En este caso se representa la heteronimia no como una estructura de ficción sino como una fábrica de mentira y de falsas monedas. Sostenemos que lejos de ser un falsificador, Pessoa propone un pensamiento del Ser y un pensamiento de la Verdad separados: el ser se aprehende por el poema y la ficción, lo cual no sucede con la Verdad (Balso \& Vásquez, 2012: 162).

Esta opinión puede que se sustente en la afirmación que realizó Pessoa: " $y$ el hecho de que no tenga una opinión filosófica ni la contraria, en lo que tiene que ver con la confección de esos "personajes-libros" no debe inducir a pensar que soy un escéptico" (Pessoa, 1987: 63). Parece que Pessoa con esta afirmación quisiera separar su yo-autor del yo al que le ocurren las cosas, pues remarca que no tiene opinión filosófica en lo que tiene que ver con la creación de los personajes, pero esto se contradecería con esa personalidad múltiple del yo histórico a la que aludía al hablar de su personalidad histérica.

Si tomamos la cita de Balso y Vásquez, observamos que refieren que, en el poema, el ser se puede aprehender, pero la Verdad no. Esto nos conduce a lo sentenciado por Jorge de Sena y recogido por Giménez (2014): “Pessoa no aspira a narrar o encontrar la verdad del mundo. [...] La forma de acercarse a la verdad, en Pessoa, es a través del sueño entendido como creación" (Giménez, 2014: 201202). Es decir, Pessoa no aspira a encontrar ni a aprehender la Verdad, pero sí a acercarse a ella, gracias a su personalidad histérica y por medio de un yo figurado múltiple. Por tanto, para ello, debía mostrar personalidades diversas y contradictorias, lo que se resuelve, si no fuera en serlo -que así se puede creer dada la personalidad múltiple confesada-, en mostrarse escéptico.

Al igual que F. Pessoa, Machado fue un poeta animado por la filosofía y no un filósofo colmando la máxima nietzscheana de: "qué lástima que lo que yo tenía entonces que decir no me atreviera a decirlo como poeta: iTal vez habría sido capaz de hacerlo! O, al menos, como filólogo" (Nietzsche, 2015: 36).

Una de las inquietudes filosóficas de nuestro poeta fue la del ser, pues, 
como bien se advierte en su prosa poética, fue un precursor de la filosofia existencial que nos encontraríamos en El ser y el tiempo. Para Machado el ser "está metafísicamente incompleto en su mismidad e identidad; más aún, constitutivamente está traspasado por la alteridad, esto es, por una apertura hacia el otro y lo Otro" (Martínez, 2013: 33). Esta apertura hacia el otro y lo Otro, halló en la poesía un medio de canalización.

Al contrario de para F. Pessoa, para quien los heterónimos surgían posterior a lo escrito, en Machado hubo, en el momento anterior a toda palabra, un imaginarse ser en potencia: "Antes de escribir un poema -decía Mairena a sus alumnos- conviene imaginar el poeta capaz de escribirlo" (Machado, 2016: 188), aquí se advierte el relieve que presenta "lo imaginado" en la obra de nuestro poeta. Como vemos en dicha cita, al enfrentarse al quehacer creativo, Machado fue consciente de que construyó un yo figurado para que lo ayudara a dialogar consigo mismo.

Por este contemplarse en heterogeneidad, consideró imprescindible apostar por el pensamiento poético y no lógico: "Al pensamiento lógico o matemático, que es pensamiento homogeneizador, a última hora pensar de la nada, se opone el pensamiento poético, esencialmente heterogeneizador" (Machado, 2016:145). Machado, como nos confirma Pablo d. A. Cobos, "le pide a Abel Marín el sentido de la poesía, de la vida y del cosmos, y Martín, luego de burlar con el nadeante pensamiento, se va a la lírica, en donde no hay espacio para la burla" (Cobos, 1972: 28).

Si la heterogeneidad del yo fue una constante en su obra, desde los poemas de Soledades, con ese tú testaferro: "¿Mi amor?... ¿recuerdas, dime / aquellos juncos tiernos, / lánguidos y amarillos que hay en el cauce seco?" (Machado, 1971: 98) y continuando por versos como: "Dijo otra verdad: / busca al tú que nunca es tuyo / ni puede erlo jamás. / [...] / Busca a tu complementario / que marcha siempre contigo, / y suele ser tu contrario / [...] no es el yoo fundamental eso que busca el poeta, / sino el tú esencial" (Machado, 1988: 629634) de Proverbios y Cantares; fue con Juan de Mairena donde ese diálogo de voces alcanzó un espacio en donde forma y dondo confluyeron. Se obseva:

una voluntad filosófica de presentar un pensamiento complejo, oblicuo a veces "diseminado en perspectivas, voces complementarias y opuestas -que son, fundamentalmente tres: la de Juan de Mairena, la de su maestro Abel Martín, metafísico idealista, y, no finalmente, sino entre estas voces, la de "Machado", o la del "narrador. que escoge selecciona y a veces comenta el pensamiento de estos [...] el contexto de "diálogo" mismo como búsqueda en común de la verdad, acorde con el concepto socrático de "filosofía" (Martínez, 2013: 9).

En cuanto al fondo, aborda diversos temas. Entre dichos apuntes, y relacionado con el tema del trabajo, encontramos algunos referentes a la esencial heterogeneidad del ser, una preocupación que hereda de su maestro: 
Abel Martín, quien: "con fe poética, no menos humana que la fe racional, creía en lo otro, en "la esencial Heterogeneidad del ser, como si dijéramos en la incurable otredad que padece lo uno"“ (Machado, 2016: 85).

Hallamos, entre ellos, otras anotaciones que aluden al escepticismo, pero uno, que lejos de ser un afán de negarlo todo, es "el único medio de salvar algo" (Cobos, 1972: 26). Así era también el escepticismo pessoano. Como afirma Barjau, para Machado es: "el punto de partida de este camino hacia el tú [...], pero no un escepticismo dogmático -aquel contra el que se dirige el argumento clásico-, sino un escepticismo escéptico" (Barjau, 1975: 48). Como expresó F. Pessoa: "afirmar es equivocarse de puerta" (Pessoa, 1987: 137). De Mairena también podría ser la sentencia que Álvaro de Campos pronuncia en el Ultimatum: "para el hombre de ciencia, el más perfecto es el más incoherente consigo mismo" (Lourenço, 1997: 64).

Para reflejar este escepticismo, tanto F. Pessoa como Machado recurrieron a crear un teatro de voces, un teatro, sí, pues para ambos era este el mejor género literario en que puede llevar a cabo sus juegos heteronímicos y apócrifos respectivamente. Si recordamos aquello que Pessoa una vez afirmó: "vuelo otro, eso es todo" (Pessoa, 1987: 36), podemos ver que es muy dramatúrgica: imaginemos: "eso es todo", justo antes de que se cierre el telón y se enciendan las luces. En esa misma carta a Joao Gaspar Simoes en que reconoce que vuela otro, un poco antes, le confiesa: "el punto central de mi personalidad como artista es que soy un poeta dramático; tengo continuamente en todo cuanto escribo la exaltación íntima del poeta y la despersonalización del dramaturgo" (Ibid: 36). Si tenemos en cuenta que lo más seguro es que Pessoa pronunciara ese "vuelo otro, eso es todo" inducido por una emoción espontánea, apreciamos que no fue algo decidible sino que ser poeta dramático fue para él serlo con la sinceridad y la inocencia de quien posee una personalidad que le aboca a ello. Y ¿qué es mudar constantemente de personalidad sino la profesión del dramaturgo y de los actores? ¿Se puede decir que el personaje de una obra de teatro ha evolucionado con respecto al de otra obra? La respuesta a esta segunda pregunta y el paralelismo con respecto a los seres de la primera lo hallamos en la contestación que Pessoa le dio a Adolfo Casais Monteiro cuando este le observó que no veía evolución en sus escritos: "no evoluciono, viajo" (Pessoa, 1987: 51).

En José Emilio Pacheco ante la heteronimia, también se incide en este universo dramático de nuestro escritor: es más, se equipara "al drama de vida que Luis Pirandello compartía acerca de su obra y la creación de personajes" (Ruelas, 2010: 101), pues como señaló Pozuelo (2010): tanto Borges, como Pessoa, Unamuno y Pirandello fueron escritores interesados por el tema de la otredad.

Del mismo modo, Balso y Vásquez aluden a este aspecto: "para Pessoa el gran poeta sea un "despersonalizado supremo" significa, [...] que es capaz de crear seres distintos a él. En eso se asemeja [...] a ese Shakespeare a quien 
Pessoa coloca en el lugar más alto entre los creadores" (Balso \& Vásquez, 2012: 159).

Muestra de la gran estima que el lusitano sentía por el dramaturgo inglés es el apartado que, en Sobre literatura y arte y dentro de "Crítica de autores", le dedica, así como las numerosas menciones que realiza de él, entre ellas: "Cuando se da un caso como el de Shakespeare, cuyo instinto psicológico se valió de ideas psiquiátricas que su época no le podía suministrar, decimos que se trata de un dramaturgo no ya de talento, sino de genio" (Pessoa, 1987: 305). A continuación Balso y Vásquez, relacionan también, pero para diferenciarlos, a Pessoa y a Pirandello. Esto desemboca en que sostengan que:

el carácter dramático de los heterónimos [...] no expresa una tragedia personal sino que combate el vagabundeo del pensamiento. La metáfora a la que recurre del "drama en gente y no en actos" señala que [...], "como" personajes de teatro, disponen en conjunto una verdad que ninguno de ellos encarna (Balso \& Vásquez, 2012: 159).

Ese vagabundeo del pensamiento está relacionado con un ser y un sentir múltiple, y con la frustración que supone tener una personalidad limitada y civil, como afirmaba Torrente Ballester y recogen Ruiz Baños y Cervera Salinas:

la materialización personal de los pensamientos o deseos incumplidos por su autor, haciéndoles "ser" y "sentir" además de pensar, de la manera que a él le hubiese gustado hacerlo y que no se corresponden con su personalidad limitada y civil, la del pobre hombre Pessoa, incapaz para la vida (Ruiz \& Cervera, 19881989: 148).

A definir personas ficticias que sintieran sinceramente los estados de alma pensados es a lo que entregó su vida F. Pessoa. A esta sinceridad se refirió F. Pessoa en una carta a Armando Côrtes-Rodrigues:

Es toda la literatura que yo he creado y vivido, que es sincera porque es sentida y constituye una corriente con posible influencia, benéfica incontestablemente, en las almas de los demás. [...] Es algo sentido en la persona del otro; está escrito dramáticamente, pero es sincero, como es sincero lo que dice el rey Lear, que no es Shakespeare, sino una creación suya. Por eso es serio todo lo que he escrito bajo los nombres de Caeiro, Reis y Campos (Pessoa, 1987: 26).

Sin embargo, esta sinceridad podría considerarse contraria a lo expresado en el poema "Autopsicografía", cuando afirma: "el poeta es un fingidor. / Finge tan complemente / que hasta finge que es dolor / el dolor que de veras siente" (Pessoa, 2012: 126). De hecho, como recoge Diego Giménez, Jorge de Sena al hacer referencia a la creación en Pessoa, cita a Nietzsche: "o poeta capaz de 
mentir / consciente, voluntariamente, / só ele é capaz de dizar a Verdade" (Sena, 1982:120. Apud Giménez (2014)). Pero si lo vemos a luz de lo que Bonati expresó al rebatir una tesis de Searle que afirmaba que el autor finge que declara, apreciamos que ambas aserciones pessoanas no son opuestas. Como muestra Pozuelo, al hacer referencia a lo dicho por Bonati: "No es que el autor de una ficción finja o simule actos, realiza actos plenos o serios, y no fingidos, lo que ocurre es que no son "actos" suyos, sino de otro" (Pozuelo, 1993: 82).

De esta manera, observamos que Pessoa, ese fingir, se lo atribuía a sí mismo como creador de la figuración de un yo plural que deviene en diversos yos autoriales, pero que una vez creados, esos yo autoriales, realizaban actos de habla sinceros, es decir, Pessoa, en ellos, pasaba a ser aquel actor que se cree y siente el papel que está representando como si fuese realmente su vida, es un "dolor que de veras siente". Por tanto, la construcción del universo dramático pessoano se basa en lo que Ortega y Gasset llamó: yo ejecutivo, esto es, en un yo te sustituyo, un yo que vive las cosas como si estuvieran siendo, un yo, que por medio de la lírica, que plantea ese espacio en el que el yo doliente es un dolor doliendo, da credibilidad al imposible ontológico de que el dolor, el odio y el deseo ajenos se sientan como propios: "El "tú" y el "él", son, pues ficticiamente "yo". En términos kantianos diríamos que mi buena voluntad hace de ti y de él como otros yo" (Ortega y Gasset, 2016: 155).

Es interesante comprobar cómo, al igual que Pessoa, Machado al asociar la creación de apócrifos con el teatro nos mencionó Shakespeare en un pasaje muy similar al significativamente citado más arriba en boca de Pessoa:

Supongamos -decía Mairena- que Shakespeare [...]se hubiera entretenido en imaginar el poema que cada uno de ellos pudo escribir [...] Es evidente que el poema de Hamlet no se parecería al de Macbeth, el de Romeo sería muy otro que el de Mercurio. Pero Shakespeare sería siempre el autor de estos poemas y el autor de los autores de estos poemas (Machado, 2016: 190).

Si a Pessoa lo que le impulsó hacia una creación que reflejara la heterogeneidad de su yo fue el deseo de universalidad y a Machado el anhelo por conocerse a sí mismo, a Unamuno fue su temor al vacío, a la vuelta a la nada, a morir. Esto, como muestra en su Sentimiento Trágico de la Vida echó sus raíces en la crisis de fe por la que estaba pasando: "cuando las dudas nos invaden y nublan la fe en la inmortalidad del alma, cobra brío y doloroso empuje el ansia de perpetuar el nombre y la fama, de alcanzar una sombra de inmortalidad siquiera" (Unamuno M.d., 1950: 358). Según L. Álvarez Catro "la literatura constituye para Unamuno el medio más asequible al individuo moderno de lograr la inmortalidad en un mundo secularizado" (Álvarez, 2015: 23). Sin embargo, nuestro autor fue consciente de que sin un lector que le diera voz a sus palabras su perpetuidad no sería posible: "Sí, lector solitario, que así atiendes / la voz de un muerto, / tuyas serán estas palabras mías / [...] / iCuando yo ya no sea 
/ serás tú, canto mío!" (Álvarez, 2015, 30). No obstante, el deseo de Unamuno de perdurar en sus escritos está condenado al fracaso, pues quien escribe no es quien exite. Aunque nuestro escritor vuelque sus estados de ánimo en sus personajes - para desdoblarse y experimentar con todas sus emociones- estos personajes terminan siempre amenazando su anhelo de ser eternidad. Los autores que ya son hitos de la Historia también suponen para él un riesgo, en su S.T.V. afirma: "Los grandes nombres del pasado nos roban lugar en él; lo que ellos ocupan en la memoria de las gentes nos lo quitarán a los que aspiramos a ocuparla" (Unamuno, M. d., 1950: 360).

Este desdoblamiento de su persona presenta, en la teoría, concomitancias con Pessoa: ambos querían sustituir a Dios. El lusitano nos dijo: "Sustitúyete siempre a ti mismo. Tú no eres bastante para ti. [...] Sustitúyete por Dios indecorosamente. Es la única actitud realmente religiosa. [...] Haz de tu ser un religión atea, de tus sensaciones un rito y un culto" (Pessoa, 1987: 137). Mientras que Unamuno en su Sentimiento Trágico de la Vida aseveró: "no es ser poseído por Dios, sino poseerle, hacerme yo Dios sin dejar de ser el yo que ahora os digo esto" (Unamuno, $M, d, 1950: 354)$. Al igual que en Unamuno, a Machado también es la ausencia de Dios, en esta ocasión como motor del mundo, la que le impulsa a sentir un mayor solipsismo (frente a Leibniz, el poeta de Castilla considera que las mónadas están solas consigo mismas) y a desear salir hacia el otro y lo otro.

Tres de las obras cumbres unamunianas reflejan esto muy bien. Su San Manuel Bueno, mártir, donde se comprueba su afán por multiplicarse en sus personajes para rehuir del limitado y vertiginoso presente (como lo denominó Borges), Niebla, donde se observa el interés porque sea el autor de carne y hueso y no los personajes quien sea eterno; y Teresa, donde sopesamos, y abrimos la posibilidad de estudio y comprobación en otro trabajo, que Rafael sea ese autor inexistente, ya con mayor independencia, que se entreveraba con Vitor Goti.

\section{Conclusiones}

Nuestros tres autores habitaron la época de las vanguardias; sin embargo, aunque el alejamiento de Machado y Unamuno con respecto a estos movimientos es evidente, en cuanto a la figura de F. Pessoa estudiosos como Marú Ruelas lo han llegado a considerar vanguardista, mientras que otros como Lourenço -cuya postura la creemos más adecuada- aclaran que, si Álvaro de Campos cantó como un futurista, no fue para realzar el nuevo mundo industrial al estilo del nuevo arte sino como una manera de sentir todo de todas las maneras, por lo que se distanció de los vanguardistas por la finalidad.

Al asumir que bajo la figura de F. Pessoa reside una personalidad neurótica, no podemos sino negar aquella afirmación que él mismo realizó sentenciando que no debíamos atribuirle un ser escéptico, y que estudiosos 
como Jorge de Sena, Balso y Vásquez han defendido. Pessoa no pretendía alcanzar una Verdad, pero sí acercarse a ella. Para ello, debía acoger -por medio de diversas figuraciones- todas las perspectivas que en su interior se reproducían, lo que deviene en ser escéptico o, si no, al menos, en mostrarse.

Tanto Pessoa como Machado hallaron en el género teatral similitud con su proceso de despersonalización. F. Pessoa habló de fingimiento y sinceridad como emociones asociadas a dicho proceso. Esto, en un primer momento, puede resultar contradictorio. Sin embargo, pensamos que, si este posible debate lo alumbramos a partir de lo expuesto por Bonati al rebatirle a Searle que el autor finge que declara, evitamos decantarnos por una de las dos opciones: fingimiento o sinceridad, presentando un punto de vista mucho más complejo y enriquecedor: el autor no finge sino que realiza actos serios lo que sucede es que no son suyos sino de otro, nos expresa Bonati.

En Machado, la despersonalización nos la encontramos vinculada al carnaval y a la ironía. Queremos aclarar que estimamos que, frente a lo propuesto por Ruelas, resulta más interesante ver en la ironía un instrumento de construcción de máscaras, y no al revés. En un primer instante, parece que la creación de apócrifos resultara de un proceso de carnavalización: existe conexión entre los apócrifos y la máscara, ambos pueden ser vistos como algo infiel a la personalidad. No obstante, sopesamos que es interesante no cerrarnos a esta visión, pues para nuestro escritor lo verdaderamente apócrifo era el mundo. Sus personajes eran los que desenmascaraban una cara que podía ser máscara.

Frente a Pessoa y Machado quienes detectaron en su histeria-neurásica y solipsismo -respectivamente- un aliciente para multiplicar su yo, para tender hacia lo otro; en Unamuno el desgarro personal proviene, no de una situación presente, sino de un temor futuro: la muerte, así como de lo que él denominó: yoización, el miedo a la imagen que los demás pudieran tener de él, el egoismo. Por tanto, aunque es innegable que en los tres autores el proceso de creación es consecuencia de una contemplación de sí mismos, descubrimos en Unamuno una consciencia de habitar en el mundo con personas ajenas a sí mismo, que no estaba en Machado ni en Pessoa. Por ello, la literatura unamuniana se sustentó sobre el temor a la no trascendencia, a que otros se la arrebataran. Si Pessoa quería ser Dios para sentirlo todo, Unamuno, para ser eterno.

No obstante, más allá de las oposiciones y analogías, de los diversos móviles y cimientos, nuestros tres autores podrían haber suscrito lo que E. Linh rezó: "pero escribí: tuve esta rara certeza, / la ilusión de tener el mundo entre las manos / iqué ilusión tan perfecta!" (Lihn, 1969: 82). 


\section{BIBLIOGRAFÍA}

ALMEIDA, R. C. B. R. d. (2014). "Ultimatum" de Álvaro de Campos. La regeneración Pessoana en el ingeniero de Tavira (Trabajo Fin de Grado). Universidad de las Islas Baleares.

ÁLVAREZ, L. (2015). Los espejos del yo. Existencialismo y metaficción en la narrativa de Unamuno. Salamanca: Ediciones Universidad de Salamanca.

BALSO, J y VÁSQUEZ, C. (2012). La heteronimia: Una ontología poética sin metafísica. Estud. Filos, 45, 149-166.

BARJAU, E. (1975). Antonio Machado: teoría y práctica del apócrifo. Barcelona: Ariel.

CERVERA, V. (2007). La poesía y la idea. Fragmentos de una vieja querella. Murcia: Universidad de Murcia.

COBOS, P. d. A. (1972). Humor y pensamiento de Antonio Machado en sus apócrifos. Madrid: Insula.

Diccionario de la Real Academia Española (1992). Madrid, España: Espasa.

ESPINO, R. F. (2015). De la colaboración como heteronimia (Tesis doctoral). Facultad de Filosofía y Letras, Universidad Autónoma de Madrid.

GIMÉNEZ, D. (2014). Fernando Pessoa: Irrealidad, escritura y desasosiego (Tesis Doctoral). Universidad de Barcelona.

JUARROZ, R. (2014). Poesía Vertical. Madrid: Cátedra.

LIHN, E. (1969). La musiquilla de las pobres esferas. Santiago de Chile: Editorial Universitaria, S.A. Recuperado de:

http://www.memoriachilena.gob.cl/archivos2/pdfs/mc0009671.pdf

LOURENÇO, A. (1997). Identidad y alteridad en Fernando Pessoa y Antonio Machado (Álvaro de Campos y Juan de Mairena). Salamanca: Ediciones Universidad de Salamanca.

MACHADO, A. (1957). Los complementarios y otras prosas póstumas. Buenos Aires: Losada, S.A.

MACHADO, A. (1971). Soledades (Poesías). Madrid: Taurus.

MACHADO, A. (1988). Poesías completas. Madrid: Espasa Calpe.

MACHADO, A. (2016). Juan de Mairena I. Madrid: Cátedra.

MACHADO, A. (2016). Juan de Mairena II. Madrid: Cátedra.

MARTíNEZ, F. (2013). Antonio Machado: la superación del solipsismo. (El escepticismo esperanzado del poeta y el pesimismo trágico del pensador de la esencial heterogeneidad del ser (Trabajo Fin de Máster). Madrid: Universidad Nacional de Educación a Distancia. 
NIETZSCHE, F. (2015). El nacimiento de la tragedia o Grecia y el pesimismo. Madrid: Alianza Editorial.

ORTEGA Y GASSET, J. (2016). La deshumanización del arte y otros ensayos de estética. Barcelona: Espasa.

PESSOA, F. (1984). Poesía. Madrid: Alianza Tres.

PESSOA, F. (1987). Sobre literatura y arte. Madrid: Alianza Editorial.

PESSOA, F. (2012). Antología Poética. El poeta es un fingidor. Madrid: Espasa Libros.

PESSOA, F. (2015). Libro del Desasosiego de Bernardo Soares. Barcelona: Seix Barral.

POZUELO, J. M. (1993). Poética de la Ficción. Madrid: Síntesis.

POZUELO, J. M. (2010). Figuraciones del yo en la narrativa. Javier Marías y E. Vila-Matas. Valladolid: Cátedra Miguel Delibes.

RUELAS, M. (2010). José Emilio Pacheco ante la heteronimia. El lado apócrifo del autor. México: Centro Universitario de Ciencias Sociales y HumanidadesUniversidad de Guadalajara. Recuperado de: http://www.publicaciones.cucsh.udg.mx/pperiod/cgraduados/pdf/sin/9_ Jose_Emilio_Pacheco_ante_la_heteronomia.pdf

RUIZ, S y CERVERA, V. (1988-1989) El escepticismo como fundamento de la heteronimia en Fernando Pessoa. Anales de Filología Hispánica, 4, 147-160.

UNAMUNO, M. (1950). Obras Selectas. Madrid: Plenitud. (2000). Teresa. Valencia: Denes. 